\title{
Use of low-dose aspirin and non-aspirin nonsteroidal anti-inflammatory drugs and risk of glioma: a case-control study
}

\author{
D Gaist ${ }^{\star}, 1$, L A García-Rodríguez ${ }^{2}$, H T Sørensen ${ }^{3}$, J Hallas ${ }^{4}$ and S Friis ${ }^{5}$
}

${ }^{1}$ Department of Neurology, Odense University Hospital, Institute of Clinical Research, Faculty of Health Sciences, University of Southern Denmark, Sdr Boulevard 29, Odense C 5000, Denmark; ${ }^{2}$ Centro Español de Investigatión Farmacoepidemiológica, c/Almirante 28, 20, Madrid 28004, Spain; ${ }^{3}$ Department of Clinical Epidemiology, Aarhus University Hospital, Olof Palmes Allé 43-45, Aarhus N 8200, Denmark; ${ }^{4}$ Clinical Pharmacology, Institute of Public Health, University of Southern Denmark, JB Winsløws Vej 19, 2.sal, Odense C 5000, Denmark and ${ }^{5}$ Danish Cancer Society Research Centre, Strandboulevarden 49, Copenhagen $\varnothing 2100$, Denmark

Background: Few studies have examined the association between use of aspirin or other non-steroidal anti-inflammatory drugs (NSAIDs) and risk of glioma and the results have been equivocal. We therefore investigated the influence of NSAID use on glioma risk in a nationwide setting.

Methods: We used national registries in Denmark to identify all patients aged 20-85 years with a first diagnosis of histologically verified glioma during 2000-2009. Each case was matched on birth year and sex to eight population controls using risk-set sampling. We used prescription data to assess NSAID use and classified exposure to low-dose aspirin or non-aspirin (NA) NSAIDs into ever use or long-term use, defined as continuous use for $\geqslant 5$ years. Conditional logistic regression was used to compute odds ratios (ORs), with 95\% confidence intervals (Cls), for glioma associated with NSAID use, adjusted for potential confounders.

Results: A total of 2688 glioma cases and 18848 population controls were included in the study. Ever use of low-dose aspirin $(\mathrm{OR}=0.90 ; 95 \% \mathrm{Cl}: 0.77-1.04)$ or NA-NSAIDs $(\mathrm{OR}=1.05 ; 95 \% \mathrm{Cl}: 0.96-1.14)$ was not associated with glioma risk. Compared with never use, long-term use of low-dose aspirin or of NA-NSAIDs was associated with ORs of 0.80 (95\% Cl: 0.53-1.21) and 1.11 (0.572.17), respectively. We observed no clear patterns of risk in stratified analysis according to estimated doses of low-dose aspirin ( $\leqslant 100 \mathrm{mg}, 150 \mathrm{mg}$ ).

Conclusion: We did not find any apparent association between aspirin or NA-NSAID use and risk of glioma, although our results may be consistent with a slight reduction in glioma risk with long-term use of low-dose aspirin.

Glioma is the most frequently diagnosed adult malignant primary brain tumour in Denmark and other Nordic countries (Lönn et al, 2004; Deltour et al, 2009). The most common histologic subtype of glioma, glioblastoma multiforme, has a 5-year survival rate of only 3.3\% (Bondy et al, 2008).

Exposure to ionising radiation is the only established environmental cause of glioma (Fisher et al, 2007; Bondy et al, 2008). However, laboratory studies of human glioma cell lines indicate that the inducible enzyme cyclooxygenase (COX)-2 is overexpressed in glioma tissue and that increasing levels of COX-2 are associated with advanced tumour grade and poor survival (Joki et al, 2000; Shono et al, 2001; Buccoliero et al, 2006; Perdiki et al, 2007).

Epidemiological studies of the effect of non-steroidal antiinflammatory drugs (NSAIDs) on the risk of brain tumours have yielded conflicting results (Thun et al, 1993; Friis et al, 2003; Sørensen et al, 2003; Ratnasinghe et al, 2004; Sivak-Sears et al,

*Correspondence: Dr D Gaist; E-mail: dgaist@health.sdu.dk

Received 7 December 2012; revised 23 January 2013; accepted 2 February 2013; published online 28 February 2013

(c) 2013 Cancer Research UK. All rights reserved 0007-0920/13 
2004; Cook et al, 2005; Scheurer et al, 2008; Rothwell et al, 2011; Daugherty et al, 2011; Ferris et al, 2012). Their inconsistent results may be explained to a large extent by methodological limitations. Assessment of long-term drug use is difficult in interview- or questionnaire-based case-control studies, and this may be particularly pertinent in patients with brain tumours, whose cognitive skills may be impaired by the growth of the tumour (Tucha et al, 2000; Teixidor et al, 2007). Moreover, most of the epidemiological studies lack sufficient statistical precision owing to the rarity of brain tumours and the likely assumption that any effect of NSAIDs varies by histological subtype of the brain tumour. As only few studies have specifically focused on the association between NSAID use and risk of glioma (Sivak-Sears et al, 2004; Scheurer et al, 2008; Daugherty et al, 2011; Ferris et al, 2012), we decided to conduct a large nationwide population-based case-control study to further investigate this association.

\section{MATERIAL AND METHODS}

The present study was designed as a nationwide case-control study based on information from the following Danish registries: Danish Cancer Registry (DCR) (Storm et al, 1997; Gjerstorff, 2011), Civil Registration System (Pedersen, 2011), National Prescription Registry (Kildemoes et al, 2011), Danish National Registry of Patients (DNRP) (Lynge et al, 2011), and Danish education and fertility registries within Statistics Denmark (Jensen and Rasmussen, 2011). Unambiguous linkage between the registries was achieved through use of the civil registration number assigned to all Danish residents since 1968, at birth or upon immigration to the country (Pedersen, 2011).

Case ascertainment. The DCR has recorded incident cases of malignant neoplasias on a nationwide basis since 1943 and has been shown to achieve almost complete ascertainment of cancer cases (Storm et al, 1997; Gjerstorff, 2011). All histological stages of central nervous system (CNS) tumours, including gliomas, are registered in the DCR. Cancer diagnoses are recorded according to the International Classification of Diseases, version 10 (ICD-10) and the ICD for Oncology (ICD-O-3) for topography and morphology codes.

Eligible cases were individuals aged 20-85 years with a first diagnosis of cranial or spinal glioma in the DCR during the period 1 January 2000-31 December 2009 and no previous history of cancer (including CNS tumours and excluding non-melanoma skin cancer). The glioma diagnosis was established on the basis of ICD-10 and histologically confirmed ICD-O-3 diagnoses (see Appendix for codes). We further classified cases according to glioma subtype, that is, glioblastoma multiforme, astrocytoma grades II and III, oligodendroglioma grades II and III, and 'other' (see Appendix Table 1). The diagnosis date recorded in the DCR was defined as the index date.

Selection of population controls. For each case, eight controls matched on birth year and sex were selected from the total Danish population using the Civil Registration System (Pedersen, 2011) and risk-set sampling (Rothman et al, 2008). The controls had to be alive and at risk for a first diagnosis of cancer (including all CNS tumours and excluding non-melanoma skin cancer) at the time the corresponding case was diagnosed (i.e., index date for both cases and controls). The Civil Registration System was used to restrict cases and controls to persons who had resided in Denmark for at least 10 consecutive years prior to the index date. As this restriction was imposed after the sampling of controls, the final ratio of cases to controls deviated slightly from 1:8.

Assessment of NSAIDs use. Information on use of NSAIDs and other drugs was obtained from the National Prescription
Registry, which contains information on all prescriptions dispensed at community pharmacies in Denmark since 1995 (Kildemoes et al, 2011). For each prescription, the Prescription Registry records the dispensing date and a full description of the dispensed product, including the anatomical therapeutic code (ATC) (WHO, 2010), size and number of dosage forms (e.g., tablets), and the total number of defined daily doses (DDD). The DDD represents the typical daily dose required by an adult when the drug is used for its main indication (WHO, 2010). Drugs used for the same indication are in principle equipotent when measured in DDD.

We retrieved all information available from the Prescription Registry from 1995 to the index date for both cases and controls. We disregarded drugs dispensed within one year prior to the index date to exclude potential drug use related to brain tumour symptoms, in order to minimise the potential for reverse causation bias (Csizmadl et al, 2007). Thus, first time use of any drug, including NSAIDs, in the year prior to the index date was classified as never use. Based on prescriptions of low-dose aspirin (ASA) or non-aspirin NSAIDs (NA-NSAIDs) (ATC codes presented in Appendix) dispensed during the period from 1995 up to 1 year prior to the index date, study subjects were classified as ever users $(\geqslant 1$ prescription) or never users (no prescriptions) of low-dose ASA or NA-NSAIDs. We classified ever use of low-dose ASA or NA-NSAIDs into recent use (latest prescription redeemed 1-2.99 years prior to index date) and past use (latest prescriptions three or more years prior to index date). We further defined continuous use of low-dose ASA or NA-NSAIDs, computed as consecutive treatment episodes defined by the dates of prescription and number of days covered by the individual prescriptions. The coverage of each prescription was calculated as the sum of DDDs (for low-dose ASA: number of pills dispensed) for the prescription plus a grace-period of 90 days. The grace-period was introduced to allow some degree of non-compliance. A continuous treatment period lasted for as long as consecutive prescriptions were presented within the time-window defined by the coverage (DDD + grace-period) of the preceding prescription. According to the timing of the most recent treatment episode in relation to index date, that is, recent or past use, the duration of continuous use was categorised into four mutually exclusive strata: $<1,1-2$, $3-4$, and $\geqslant 5$ years.

For low-dose ASA, we calculated an estimated daily dose defined as the most frequently prescribed tablet size during the exposure period. This was categorised as a 'low' ( $\leqslant 100 \mathrm{mg}$ ) or 'high' (150 mg) daily dose of low-dose ASA, assuming that the vast majority of low-dose ASA users took one tablet daily. For NA-NSAIDs, we assumed that most patients receiving long-term therapy had a daily use corresponding to the DDD for the individual drugs. Therefore, we did not estimate daily doses of NA-NSAIDs.

Finally, we performed separate analyses for the two most frequently prescribed NA-NSAIDs in Denmark, that is, ibuprofen and diclofenac.

Potential confounders. Patients suffering from stroke are frequently prescribed low-dose ASA and typically undergo neuroimaging, which in some instances reveals concomitant gliomas. We thus included information on history of stroke obtained from the DNRP (see ICD codes in Appendix), which contains inpatient data (from 1977 onwards) and outpatient data (from 1995 onwards) for all non-psychiatric hospitals in Denmark, including dates of admission/contact and diagnosis codes.

A recent meta-analysis of 12 observational studies reported an inverse association between allergy (asthma, eczema, and hay fever) and risk of glioma (Chen et al, 2011). A history of allergy or asthma recorded in the DNRP was therefore included as a potential confounder (see ICD codes in Appendix Table 1). 
As diabetes is under intense scrutiny for its possible association with cancer risk (Carstensen et al, 2012), and is potentially associated with ASA use, we classified study subjects as diabetics if they had a history of diabetes mellitus according to the DNRP (Lynge et al, 2011) or had redeemed prescriptions for antidiabetic drugs prior to the index date (see ATC codes in the Appendix). We also considered certain other drugs as potential confounders, including postmenopausal hormone replacement therapy (HRT), statins, antihistamines, and anti-asthma medications (ATC codes in Appendix). Study subjects were classified according to use ( $\geqslant 1$ prescription one or more years prior to the index date) or no use (no prescriptions) of these drugs.

We used parity as a proxy measure for exposure to endogenous sex hormones in women, as female sex hormones may influence glioma risk (Fisher et al, 2007). Parity was assessed for female cases and controls based on information in the nationwide Fertility Database (Blenstrup and Knudsen 2011). Female study subjects were classified into the following categories according to number of live births: 0 (nullipara), 1, 2, 3+, or 'missing information'.

As a marker of socioeconomic status, we included information on highest educational level achieved by study subjects according to annually updated information from registries at Statistics Denmark (Jensen and Rasmussen 2011). We divided study subjects into three categories according to number of years of schooling (7-10, 11-12, and $13+$ years).

Statistical analysis. Cases and controls were matched on age (birth year), sex, and year of index date. We used conditional logistic regression to compute adjusted odds ratios (and 95\% CIs) for glioma associated with low-dose ASA or NA-NSAID use, adjusting for years of schooling, history of diabetes, stroke, allergy or asthma, and use of statins, antihistamines or anti-asthma medication. We also performed analyses restricting cases to glioblastoma multiforme. Information on HRT use and parity was included only in sensitivity analyses restricted to female study subjects. Finally, we examined the presence of potential effect measure modification of age, by stratifying analyses according to the median age of the study subjects. All analyses were performed using Stata SE 12.1 (StataCorp, College Station, TX, USA). The study was approved by the Danish Data Protection Agency and the Danish Medicines Agency.

\section{RESULTS}

Our study population consisted of 2688 cases and 18848 controls. Of these, 1606 cases (59.8\%) and 11656 controls (61.8\%) were male. Cases and controls were also similar with regard to the distribution of age, parity, years of schooling, prevalence of diabetes, stroke, allergy, asthma, and use of NSAIDs, statins, antiasthmatics and antihistamines, and HRT (Table 1).

Ever use of low-dose ASA (OR $=0.90 ; 95 \%$ CI: $0.77-1.04)$ or NA-NSAIDs $(\mathrm{OR}=1.05$; 95\% CI: $0.96-1.14)$ were not associated with risk of glioma. These risk estimates were not markedly influenced by recency of drug use (Table 2), and similar risk estimates were also found for recent long-term use ( $\geqslant 5$ years) of low-dose ASA and NA-NSAIDs (Table 3). Classification of duration of use as continuous had limited influence on the results (Table 3). The risk of glioma associated with ever use of low-dose ASA was slightly lower for estimated daily doses of $150 \mathrm{mg}$ $(\mathrm{OR}=0.82 ; \quad 95 \% \quad \mathrm{CI}: \quad 0.67-1.01) \quad$ compared with $\leqslant 100 \mathrm{mg}$ $(\mathrm{OR}=0.90$; CI: 0.75-1.09) ASA (Table 4). Risk estimates for ever use of ibuprofen or diclofenac were similar to those for total use of NA-NSAIDs (data not presented).

In analyses restricted to cases of glioblastoma multiforme $(n=1561)$ and their matched controls, long-term continuous use of low-dose ASA or NA-NSAIDs were associated with ORs of 0.88
Table 1. Characteristics of study subjects in a nationwide case-control study of glioma in Denmark, 2000-2009

\begin{tabular}{|c|c|c|}
\hline Characteristic & $\begin{array}{c}\text { Cases } \\
(\mathbf{N}=\mathbf{2 6 8 8})\end{array}$ & $\begin{array}{c}\text { Controls } \\
(\mathbf{N}=18848)\end{array}$ \\
\hline \multicolumn{3}{|l|}{ Gender } \\
\hline $\begin{array}{l}\text { Female } \\
\text { Male }\end{array}$ & $\begin{array}{l}1082(40.3) \\
1606(59.8)\end{array}$ & $\begin{array}{r}7192(38.2) \\
11656(61.8)\end{array}$ \\
\hline
\end{tabular}

\begin{tabular}{|l|c|c|}
\hline Age (years) & $119(4.4)$ & $789(4.2)$ \\
\hline $20-29$ & $215(8.0)$ & $1487(7.9)$ \\
$30-39$ & $422(15.7)$ & $3033(16.1)$ \\
$40-49$ & $692(25.7)$ & $5019(26.6)$ \\
$50-59$ & $742(27.6)$ & $5231(27.8)$ \\
$60-69$ & $434(16.2)$ & $2896(15.4)$ \\
$70-79$ & $64(2.4)$ & $393(2.1)$ \\
$80-85$ & &
\end{tabular}

Parity, number of children ${ }^{a, b}$

\begin{tabular}{|l|c|c|}
\hline 0 & $97(9.0)$ & $658(9.2)$ \\
1 & $167(15.4)$ & $1122(15.6)$ \\
2 & $419(38.7)$ & $2739(38.1)$ \\
$3+$ & $241(22.3)$ & $1668(23.2)$ \\
Missing & $158(14.6)$ & $1005(14.0)$
\end{tabular}

Schooling, number of years

\begin{tabular}{|l|c|c|}
\hline $7-10$ & $951(35.4)$ & $6535(34.7)$ \\
$11-12$ & $1100(40.9)$ & $7754(41.1)$ \\
$13+$ & $594(22.1)$ & $4196(22.3)$ \\
Missing & $43(1.6)$ & $363(1.9)$
\end{tabular}

Morbidity

\begin{tabular}{|l|l|l|}
\hline Diabetes & $94(3.5)$ & $820(4.4)$ \\
Stroke & $72(2.7)$ & $430(2.3)$ \\
Allergy & $67(2.5)$ & $512(2.7)$
\end{tabular}

\section{Drug use}

Aspirin, low-dose

Non-aspirin NSAIDs ${ }^{c}$

Selective cox2-inhibitors

Statins

Anti-asthma drugs

Antihistamines

Postmenopausal hormone

replacement therapy ${ }^{a}$

\begin{tabular}{c|c}
$320(11.9)$ & $2405(12.8)$ \\
$1588(59.1)$ & $10945(58.1)$ \\
$160(6.0)$ & $963(5.1)$ \\
$214(8.0)$ & $1644(8.7)$ \\
$307(11.4)$ & $2311(12.3)$ \\
$237(8.8)$ & $1705(9.1)$ \\
$295(27.3)$ & $2130(29.6)$
\end{tabular}

Abbreviation: NSAIDs $=$ nonsteroidal anti-inflammatory drugs. Numbers are expressed in percentages.

a Women only.

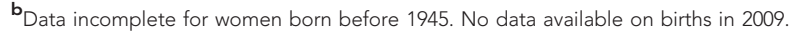

${ }^{c}$ Non-steroidal anti-inflammatory drugs including Cox2-inhibitors.

(95\% CI: 0.54-1.42) and 1.56 (95\% CI: 0.71-3.46), respectively. There were too few data on other types of gliomas to allow a formal analysis of their association with ASA or NA-NSAID use.

For both ASA and NA-NSAID, we observed no apparent risk variation according to age ( $<$ and $\geqslant 58$ years; data not shown). Finally, we performed a number of sensitivity analyses. First, we repeated all analyses after (1) redefining the 'non-use' reference group to more than two prescriptions, (2) introducing a lag-time of 2 years prior to the index date, (3) introducing varying length of the grace periods (60 or 120 days) used to compute treatment episodes, and (4) using cumulative use of NSAID (total treatment period during the exposure period regardless of whether the treatment was continuous or not) instead of continuous use. 
Furthermore, for NA-NSAIDs, we also calculated intensity of use, that is, total number of DDD divided by time period between first and last prescription, and classified this into tertiles. Subsequently, we performed analyses comparing glioma risk associated with long-term, high-intensity use (upper tertile) with never use of NANSAIDs. Finally, analyses with women in separate strata were repeated with HRT and parity included as confounder variables. The results of all sensitivity analyses were similar to those of the main analyses (data not presented).

\section{DISCUSSION}

We found that long-term use of NA-NSAIDs was not associated with reduced risk of glioma. However, our findings may be consistent with a small reduction in glioma risk associated with the

Table 2. Ever use of nonsteroidal anti-inflammatory drugs and risk of glioma

\begin{tabular}{|c|c|c|c|c|}
\hline & Cases & Controls & $\begin{array}{l}\text { Crude odds } \\
\text { ratio }(95 \% \mathrm{Cl})\end{array}$ & $\begin{array}{l}\text { Adjusted odds } \\
\text { ratio }^{\text {a }}(95 \% \mathrm{Cl})\end{array}$ \\
\hline \multicolumn{5}{|c|}{ Aspirin, low-dose } \\
\hline $\begin{array}{l}\text { Never } \\
\text { Ever } \\
\text { Recent }^{b} \\
\text { Past }^{c}\end{array}$ & $\begin{array}{c}2368 \\
320 \\
270 \\
50\end{array}$ & $\begin{array}{c}16443 \\
2405 \\
2003 \\
402\end{array}$ & $\begin{array}{c}1 \text { (reference) } \\
0.89(0.78-1.01) \\
0.91(0.79-1.05) \\
0.81(0.59-1.09)\end{array}$ & $\begin{array}{r}1 \text { (reference) } \\
0.90(0.77-1.04) \\
0.91(0.77-1.07) \\
0.80(0.59-1.09)\end{array}$ \\
\hline \multicolumn{5}{|c|}{ Non-aspirin NSAIDs } \\
\hline $\begin{array}{l}\text { Never } \\
\text { Ever } \\
\text { Recent }^{\text {b }} \\
\text { Past }^{c}\end{array}$ & $\begin{array}{l}1100 \\
1588 \\
800 \\
788\end{array}$ & $\begin{array}{c}7903 \\
10945 \\
5408 \\
5537\end{array}$ & $\begin{array}{r}1 \text { (reference) } \\
1.04(0.96-1.13) \\
1.04(0.94-1.15) \\
1.04(0.94-1.15)\end{array}$ & \begin{tabular}{|r|}
1 (reference) \\
$1.05(0.96-1.14)$ \\
$1.06(0.95-1.17)$ \\
$1.05(0.94-1.17)$
\end{tabular} \\
\hline \multicolumn{5}{|c|}{ 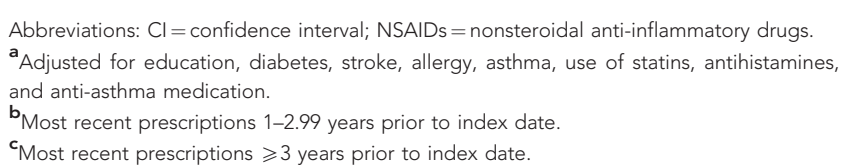 } \\
\hline
\end{tabular}

long-term use of low-dose ASA. These findings should be interpreted cautiously due to limited statistical precision, notably in the duration and dose-response analyses.

Some previous case-control studies, all based on self- or proxyreported data on drug use, have reported an inverse association between use of NSAIDs and risk of glioma (Scheurer et al, 2008; Ferris et al, 2012) or glioblastoma multiforme (Sivak-Sears et al, 2004). These results were not supported by a recent cohort study (Daugherty et al, 2011), based on 341 incident cases of glioma among 302767 individuals, that reported null results for the association between regular use of ASA or NA-NSAIDs and risk of glioma. Other prospective studies lacked sufficient statistical precision to evaluate brain tumours by histologic type. The majority of these studies did not find a reduced risk of brain tumours associated with ASA or NA-NSAID use (Thun et al, 1993; Friis et al, 2003; Sørensen et al, 2003; Ratnasinghe et al, 2004;
Table 4. Dose of aspirin and risk of glioma

\begin{tabular}{|c|c|c|c|}
\hline & Cases & Controls & $\begin{array}{l}\text { Adjusted odds } \\
\text { ratio }^{\text {a }}(95 \% \mathrm{Cl})\end{array}$ \\
\hline Never use & 2368 & 16443 & 1 (reference) \\
\hline \multicolumn{4}{|l|}{$\leqslant 100 \mathrm{mg}^{\mathrm{b}}$} \\
\hline Ever use & 180 & 1357 & $0.90(0.75-1.09)$ \\
\hline $\begin{array}{l}\text { Recent, continuous } \\
\quad<5 \text { years } \\
\geqslant 5 \text { years }\end{array}$ & $\begin{array}{c}156 \\
141 \\
15\end{array}$ & $\begin{array}{c}1178 \\
1061 \\
117\end{array}$ & $\begin{array}{l}0.90(0.74-1.11) \\
0.90(0.73-1.12) \\
0.88(0.50-1.56)\end{array}$ \\
\hline \multicolumn{4}{|l|}{$150 \mathrm{mg}^{\mathrm{b}}$} \\
\hline Ever use & 140 & 1048 & $0.82(0.67-1.01)$ \\
\hline $\begin{array}{l}\text { Recent, continuous } \\
\quad<5 \text { years } \\
\geqslant 5 \text { years }\end{array}$ & $\begin{array}{c}114 \\
98 \\
16\end{array}$ & $\begin{array}{l}825 \\
690 \\
135\end{array}$ & $\begin{array}{l}0.85(0.68-1.07) \\
0.87(0.69-1.11) \\
0.74(0.42-1.29)\end{array}$ \\
\hline \multicolumn{4}{|c|}{$\begin{array}{l}\text { Abbreviation: } \mathrm{Cl}=\text { confidence interval. } \\
\text { a Adjusted for education, diabetes, stroke, allergy, asthma, use of statins, antihistamines, } \\
\text { and anti-asthma medications. } \\
{ }^{b} \text { In users of more than one dose of aspirin, the most frequently used dose was chosen. }\end{array}$} \\
\hline
\end{tabular}

Table 3. Duration of use of nonsteroidal anti-inflammatory drugs and risk of glioma

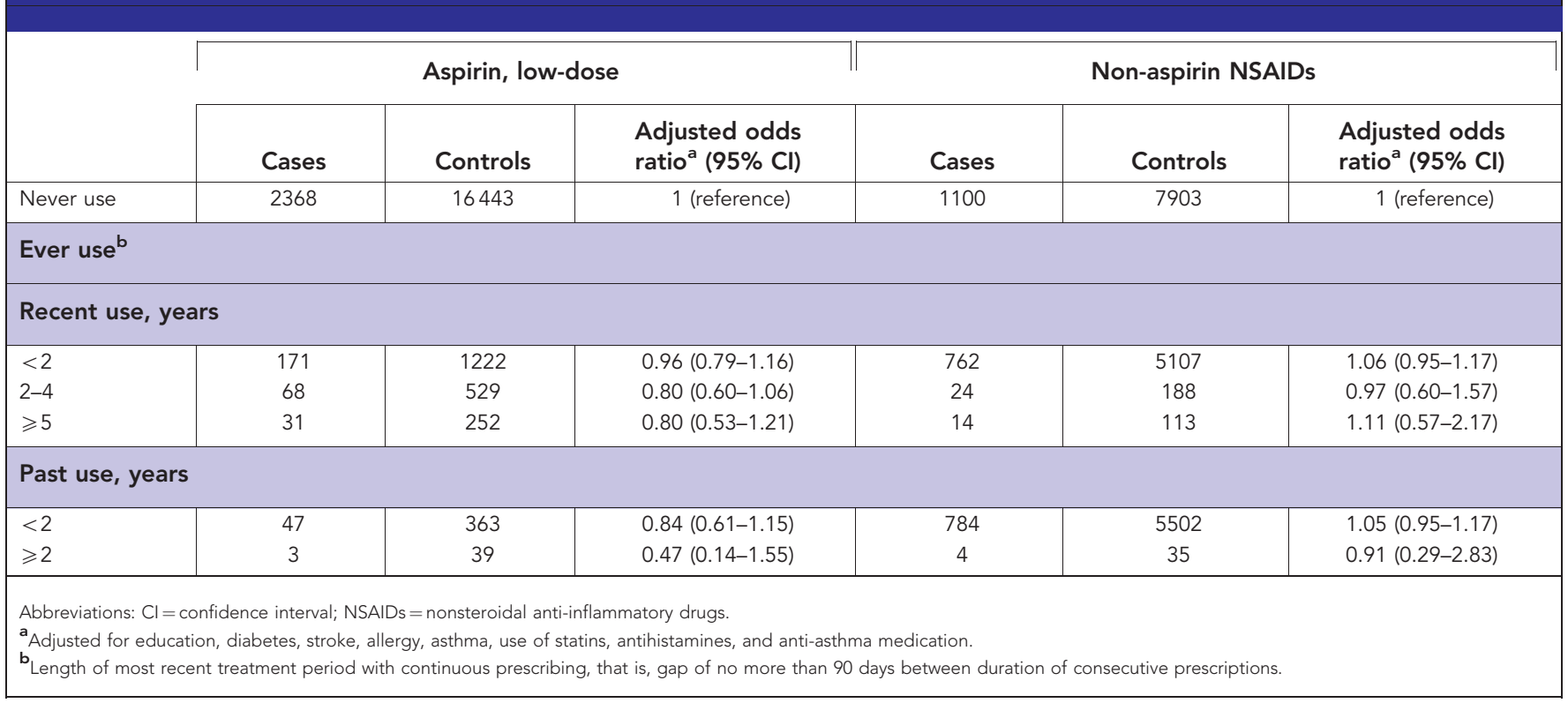


Cook et al, 2005). A notable exception is a recent post-trial analysis of individuals who participated in randomized clinical trials of ASA and cardiovascular disease (Rothwell et al, 2011). In that study, a subanalysis for brain tumour, based on small numbers, indicated that long-term use of low-dose ASA was associated with a substantially reduced risk of death (hazard ratio $=0.31 ; 95 \% \mathrm{CI}$ : 0.11-0.89) due to primary brain tumours during the first 10 years following randomisation, but not thereafter (hazard ratio $=1.16 ; 95 \%$ CI: (0.49-2.77) (Rothwell et al, 2011). Our results are more in line with the majority of other cohort studies, including the only cohort study that specifically examined risk of glioma associated with NSAID use (Daugherty et al, 2011). We believe this may be due to our ascertainment of drug use through registries. We thus eliminated recall bias, a potential methodological shortcoming of previous case-control studies.

Our study has a number of other strengths. We used nationwide registries with complete coverage and continuously collected data on all Danish residents, an approach that minimised selection bias. The DCR enabled us to identify incident cases of glioma and cancer-free controls with minimal misclassification. We also restricted our sample to histologically verified cases, which enhanced case validity and allowed us to perform analyses on subtypes of glioma.

A number of potential limitations should also be noted. Overthe-counter use of NSAIDs is not recorded in the Prescription Registry. However, in Denmark in 2009, 90\% of low-dose ASA and $81 \%$ of NA-NSAIDs were purchased through prescriptions (www.medstat.dk/en). Among NA-NSAIDs, only low-dose (200 mg) ibuprofen was available over-the-counter in Denmark in the study period. We therefore believe that over-the-counter use only resulted in minor misclassification of low-dose ASA and NANSAID use. High-dose ASA is primarily sold over-the-counter in Denmark and we could therefore not directly account for its use in our study. However, in Denmark high-dose ASA is used primarily for the relief of acute pains, that is, backaches, headaches, sports injuries and so on, and is thus mainly used as short-term therapy that most likely has limited, if any, biological effect on risk of glioma.

Since the Prescription Registry was established in 1995, drug histories only spanned 5-15 years, depending on index date. This left-truncation of prescription data may induce two potential problems. First, study subjects who stopped using NSAIDs prior to 1995 were misclassified as never users in our study. Second, the duration of current use may be underestimated in subjects with NSAID use prior to 1995. Such misclassifications would most likely result in a conservative misclassification bias, that is, attenuation of the association between NSAID use and glioma risk. Examining NSAID prescription data from a regional registry (OPED) with complete coverage of a Danish county (Funen) since 1990, we found that the extent of misclassification due to left truncation of NSAID use is probably minor in the present study (Hallas, personal communication).

Lifestyle factors could also influence our findings if such factors were both related to the likelihood of being prescribed NSAIDs and the risk of glioma. We find this scenario unlikely, as risk of glioma has not been convincingly linked to lifestyle factors (Bondy et al, 2008). Residual confounding by socioeconomic indicators might also have influenced our results, as we only adjusted the analyses for highest achieved level of schooling. A Danish study, however, based on DCR data found no association between socioeconomic status and incidence of CNS tumours (Schmidt et al, 2008). Therefore, we believe that lifestyle factors and socioeconomic status are not likely to have substantially affected our findings.

It is conceivable that, prior to detection, brain tumours could exert an influence on adherence to medication use, for example, by affecting cognitive skills. However, by disregarding NSAID use in the year prior to the index date, we believe that we have minimised the impact of such effects. This conclusion was reinforced by the fact that neither increasing the lag-time to 2 years or restricting analyses to cases of glioblastoma multiforme, a glioma subtype with well-established rapid development, had significant influence on our results.

In conclusion, we did not find any apparent association between ASA or NA-NSAIDs use and glioma risk, although there was some indication of a slightly reduced overall risk of glioma with longterm use of low-dose ASA. Analyses of longer durations are warranted to test whether the effect of low-dose ASA becomes stronger or if NA-NSAIDs confer a reduced risk.

\section{ACKNOWLEDGEMENTS}

This study was supported by grants from the Danish Cancer Society (grant no. R56-A2879), Odense University Hospital, and the University of Southern Denmark.

\section{DISCLAIMER}

The funding sources had no role in the design, analysis, and interpretation of the results. Thus, the authors were independent from the funding sources.

\section{REFERENCES}

Blenstrup LT, Knudsen LB (2011) Danish registers on aspects of reproduction. Scand J Public Health 39(7 Suppl): 79-82.

Bondy ML, Scheurer ME, Malmer B, Barnholtz-Sloan JS, Davis FG, Il'yasova D, Kruchko C, McCarthy BJ, Rajaraman P, Schwartzbaum JA, Sadetzki S, Schlehofer B, Tihan T, Wiemels JL, Wrensch M, Buffler PA (2008) Brain tumor epidemiology: consensus from the brain tumor epidemiology consortium. Cancer 113(Suppl 7): 1953-1968.

Buccoliero AM, Caldarella A, Gheri CF, Taddei A, Paglierani M, Pepi M, Mennonna P, Taddei GL (2006) Inducible cyclooxygenase (COX-2) in glioblastoma-clinical and immunohistochemical (COX-2-VEGF) correlations. Clin Neuropathol 25: 59-66.

Carstensen B, Witte DR, Friis S (2012) Cancer occurrence in Danish diabetic patients: duration and insulin effects. Diabetologia 55: 948-958.

Chen C, Xu T, Chen J, Zhou J, Yan Y, Lu Y, Wu S (2011) Allergy and risk of glioma: a meta-analysis. Eur J Neurol 18: 387-395.

Cook NR, Lee IM, Gaziano JM, Gordon D, Ridker PM, Manson JE, Hennekens CH, Buring JE (2005) Low-dose aspirin in the primary prevention of cancer: the Women's Health Study: a randomized controlled trial. JAMA 294: 47-55.

Csizmadl I, Collet J-P, Boivin J (2007) Bias and confounding in pharmacoepidemiology. In Strom BL (eds.) 4th edn. Pharmacoepidemiology. Wiley and sons: West Sussex, pp 791-810.

Daugherty SE, Moore SC, Pfeiffer RM, Inskip PD, Park Y, Hollenbeck A, Rajaraman P (2011) Nonsteroidal anti-inflammatory drugs and glioma in the NIH-AARP Diet and Health Study cohort. Cancer Prev Res 4: 2027-2034.

Deltour I, Johansen C, Auvinen A, Feychting M, Klaeboe L, Schüz J (2009) Time trends in brain tumor incidence rates in Denmark, Finland, Norway, and Sweden, 1974-2003. J Natl Cancer Inst 101: 1721-1724.

Ferris J, McCoy L, Neugut A, Wrensch M, Lai R (2012) HMG CoA reductase inhibitors, NSAIDs and risk of glioma. Int J Cancer 131(6): E1031-E1037.

Fisher JL, Schwartzbaum JA, Wrensch M, Wiemels JL (2007) Epidemiology of brain tumors. Neurol Clin 25: 867-890.

Friis S, Sørensen HT, McLaughlin JK, Johnsen SP, Blot WJ, Olsen JH (2003) A population-based cohort study of the risk of colorectal and other cancers among users of low-dose aspirin. Br J Cancer 88: 684-688.

Gjerstorff ML (2011) The Danish Cancer Registry. Scand J Public Health 39(7 Suppl): 42-45. 
Jensen VM, Rasmussen AW (2011) Danish education registers. Scand J Public Health 39(7 Suppl): 91-94.

Joki T, Heese O, Nikas DC, Bello L, Zhang J, Kraeft SK, Seyfried NT, Abe T, Chen LB, Carroll RS, Black PM (2000) Expression of cyclooxygenase 2 (COX-2) in human glioma and in vitro inhibition by a specific COX-2 inhibitor, NS-398. Cancer Res 60: 4926-4931.

Kildemoes HW, Toft Sørensen H, Hallas J (2011) The Danish National Prescription registry. Scand J Public Health 39(7 Suppl): 38-41.

Lynge E, Sandegaard JL, Rebolj M (2011) The Danish National Patient Register. Scand J Public Health 39(7 Suppl): 30-33.

Lönn S, Klaeboe L, Hall P, Mathiesen T, Auvinen A, Christensen HC, Johansen C, Salminen T, Tynes T, Feychting M (2004) Incidence trends of adult primary intracerebral tumors in four Nordic countries. Int $J$ Cancer 108: $450-455$

Pedersen CB (2011) The Danish Civil Registration System. Scand J Public Health 39(7 Suppl): 22-25.

Perdiki M, Korkolopoulou P, Thymara I, Agrogiannis G, Piperi C, Boviatsis E, Kotsiakis X, Angelidakis D, Diamantopoulou K, Thomas-Tsagli E, Patsouris E (2007) Cyclooxygenase-2 expression in astrocytomas. Relationship with microvascular parameters, angiogenic factors expression and survival. Mol Cell Biochem 295: 75-83.

Ratnasinghe LD, Graubard BI, Kahle L, Tangrea JA, Taylor PR, Hawk E (2004) Aspirin use and mortality from cancer in a prospective cohort study. Anticancer Res 24: 3177-3184.

Rothman K, Greenland S, Lash TL (2008) Modern Epidemiology3rd Edn.Wolters Kluwer Health. Lippincott Williams \& Wilkins: Philadelphia.

Rothwell PM, Fowkes FG, Belch JF, Ogawa H, Warlow CP, Meade TW (2011) Effect of daily aspirin on long-term risk of death due to cancer: analysis of individual patient data from randomised trials. Lancet 377: 31-41.

Scheurer ME, El-Zein R, Thompson PA, Aldape KD, Levin VA, Gilbert MR, Weinberg JS, Bondy ML (2008) Long-term anti-inflammatory and antihistamine medication use and adult glioma risk. Cancer Epidemiol Biomarkers Prev 17: 1277-1281.

\section{APPENDIX}

Table 1. List of ICD-10, ICD-O-3, and ATC codes

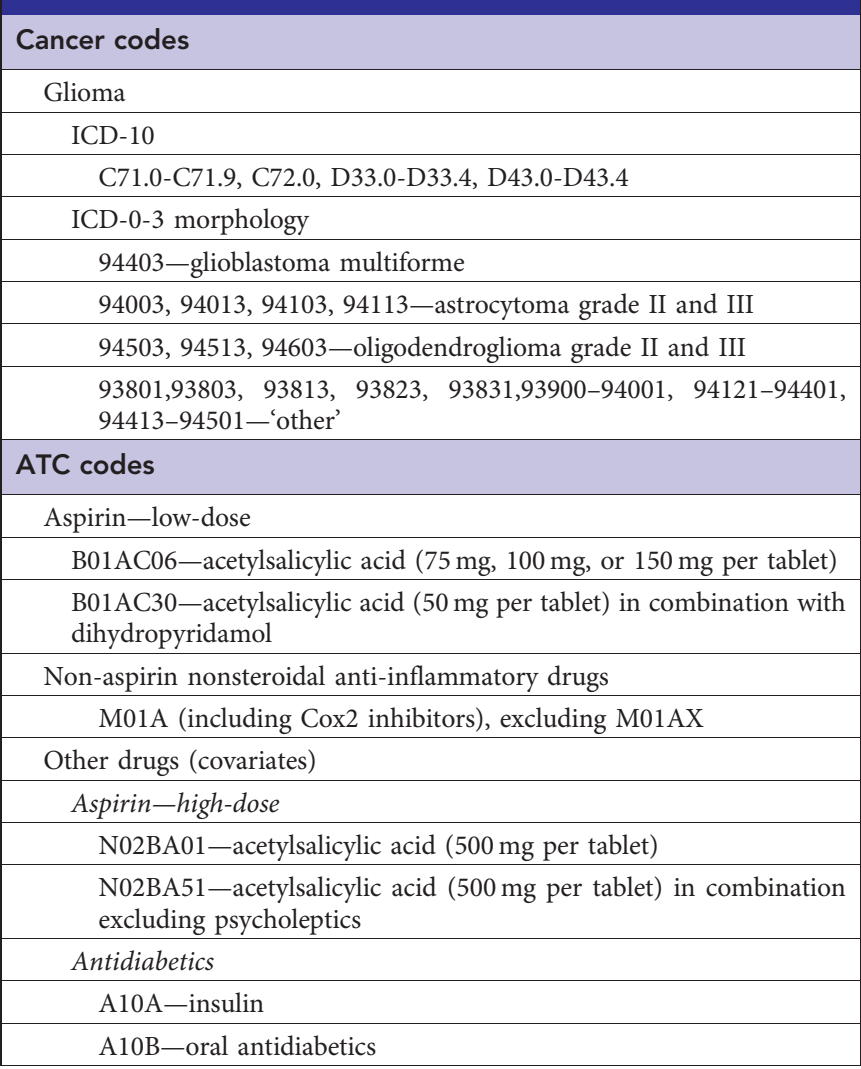

Schmidt LS, Nielsen H, Schmiedel S, Johansen C (2008) Social inequality and incidence of and survival from tumours of the central nervous system in a population-based study in Denmark, 1994-2003. Eur J Cancer 44: 2050-2057.

Shono T, Tofilon PJ, Bruner JM, Owolabi O, Lang FF (2001) Cyclooxygenase2 expression in human gliomas: prognostic significance and molecular correlations. Cancer Res 61: 4375-4381.

Sivak-Sears NR, Schwartzbaum JA, Miike R, Moghadassi M, Wrensch M (2004) Case-control study of use of nonsteroidal antiinflammatory drugs and glioblastoma multiforme. Am J Epidemiol 159: 1131-1139.

Storm HH, Michelsen EV, Clemmensen IH, Pihl J (1997) The Danish Cancer Registry - history, content, quality and use. Dan Med Bull 44: 535-539.

Sørensen HT, Friis S, Nørgård B, Mellemkjaer L, Blot WJ, McLaughlin JK, Ekbom A, Baron JA (2003) Risk of cancer in a large cohort of nonaspirin NSAID users: a population-based study. Br J Cancer 88: 1687-1692.

Teixidor P, Gatignol P, Leroy M, Masuet-Aumatell C, Capelle L, Duffau H (2007) Assessment of verbal working memory before and after surgery for low-grade glioma. J Neurooncol 81: 305-313.

Thun MJ, Namboodiri MM, Calle EE, Flanders WD, Heath Jr. CW (1993) Aspirin use and risk of fatal cancer. Cancer Res 53: 1322-1327.

Tucha O, Smely C, Preier M, Lange KW (2000) Cognitive deficits before treatment among patients with brain tumors. Neurosurgery 47: 324-333.

WHO (2010) Collaborating Centre for Drug Statistics Methodology. Guidelines for ATC classification and DDD assignment 2011. Oslo.

This work is published under the standard license to publish agreement. After 12 months the work will become freely available and the license terms will switch to a Creative Commons AttributionNonCommercial-Share Alike 3.0 Unported License.

\section{Table 1. (Continued)}

Allergy and asthma

R06A-antihistamines

R03-anti-asthma drugs

Hormone replacement therapy

G03C, G03D, G03F, G03HB01

Statins

C10AA01-Simvastatin

C10AA02-Lovastatin

C10AA03-Pravastatin

C10AA04-Fluvastatin

C10AA05-Atorvastatin

C10AA06-Cerivastatin

C10AA07-Rosuvastatin

Hospital discharge codes

Diabetes

ICD-8: 249, 250

ICD-10: E10-E14

Stroke

ICD-8: 431, 433, 434

ICD-10: I60, I61, I63

Allergy and asthma

ICD-8: 493, 507, 708, 69200, 69202, 69210, 69212, 69220, 69222, $69230,69232,69260,69262$

ICD-10: J45, J46, J30, L50, L23

Abbreviations: $A T C=$ Anatomical, therapeutical, chemical; ICD $=$ International classification of diseases. 